\title{
Teoria de autodeterminação utilizada em mundos virtuais, um estudo de caso.
}

\author{
Fabiana Santiago Sgobbi ${ }^{1}$, Liane Margarida Rockenbach Tarouco ${ }^{2}$ \\ ${ }^{1}$ Pós-Doutoranda em Informática na Educação - UFRGS - fabiana.sgobbi@ufrgs.br \\ ${ }^{2}$ Professora titular da UFRGS, junto ao PPGIE - liane@ penta.ufrgs.br
}

Resumo: Esta pesquisa investigou o impacto da combinação de mundos virtuais 3D com dispositivos móveis, agentes conversacionais e sensor de movimentação, como elementos capazes de promover a motivação de sujeitos envolvidos em um programa de controle de obesidade, fator de alta relevância uma vez que o tratamento personalizado tem alto custo e a obesidade é um problema mundial. Este conjunto de tecnologias foi utilizado como estratégia de apoio com vistas a oferecer ao usuário a sensação de "estar presente" num contex to especialmente preparado para promover a motivação e aprendizagem com a interação com objetos 3D. Este traz um recorte sobre a teoria da autodeterminação e como pode ser trabalhada com os dispositivos de Internet das coisas e agentes conversacionais em mundo virtuais.

Palavras chaves: Autodeterminação, mundo virtual, sensores.

The theory of self-determination used in virtual worlds, a case study.

Abstract: This research investigated the impact of the combination of virtual 3D virtual worlds with mobile devices and conversational agents and movement sensors, as elements capable of promoting the motivation of subjects involved in an obesity control program, a highly relevant factor since the treatment cost is a problem worldwide. This set of technologies was used as a support strategy to offer the user the sensation of being present in a context specially prepared to promote motivation and learning through interaction with 3D objects. This brings a clipping about the theory of self-determination and how it can be worked with the Internet devices of things and conversational agents in virtual worlds

Keywords: Self-determination, virtual world, sensors.

\section{Introdução}

A tecnologia atualmente disponível permite delinear soluções inovadoras para problemas que afetam a saúde de uma parcela apreciável da população, tal como a obesidade. A obesidade é um dos problemas mais importantes de Saúde Pública no Brasil e em muitos outros países, conforme aponta a Organização Mundial de Saúde (OMS). O sucesso do tratamento das doenças crônicas, como é o caso da obesidade, depende, fortemente, da participação e do comprometimento do indivíduo que precisa envolver-se ativamente e de forma persistente no tratamento. Desta forma, foram pesquisados um conjunto de tecnologias capaz de trabalhar a sensação de "estar presente" com participante, buscando ensejar o autocuidado.

A pesquisa realizada, teve intuito de investigar uma solução alternativa de baixo custo e fácil acesso, envolvendo mundo virtual imersivo e Internet das Coisas, para isto, foi desenvolvido um sistema que agregou a sensação de interação humana, apoio social e engajamento com a utilização de tecnologias emergentes, mundos virtuais com agentes conversacionais personificados, sensores e smartphone que interagem com participante, afim de promover motivações, aprendizagem, mudança de comportamento e ganhos em qualidade de vida. 
Este artigo traz um recorte, específico do referencial teórico e como este foi aplicado. Nesta pesquisa foi construído um sistema denominado HIGIA (Habit Individualizado e Guia Interativo de Atitudes) que combinou tecnologias emergentes (mundos virtuais imersivos com a criação de agentes conversacionais interagindo com os usuários para apresentar e comentar/explicar os dados derivados de sensores de movimentação e enviar mensagem e alertas no smartphone) com vistas a ensejar a motivação para autocuidado para controle de obesidade. Subsídio teórico foi derivado da teoria da autodeterminação de Ryan e Deci (2000), a qual será explorada na próxima seção.

Na terceira seção será apresentada a metodologia aplicada na pesquisa, dando ênfase ao referencial teórico e na sequência será explanado a análise final e a forma de utilizar os questionários de autorregulação, na última seção serão expostas as conclusões.

\section{Referencial teórico}

A motivação é uma ideia central na Teoria da Autodeterminação (TAD). Os primeiros trabalhos baseados nessa teoria surgiram nos anos 70, mas, em meados dos anos 80, a TAD se afirmou com as pesquisas de Deci e Ryan (1985), Ryan e Connell (1989). Essencialmente, na década de 2000, a investigação no âmbito da TAD cresceu (DECI \& RYAN, 2008) mais rapidamente e se afirmou na comunidade científica. $O$ estudo da motivação implica explorar a energia e direção do comportamento, e, somente quando esses dois aspectos são contemplados, podemos falar, verdadeiramente, de teorias da motivação em psicologia (DECI \& RYAN, 1985).

Diz-se que a pessoa está motivada quando esta se sente ativa e com energia para atingir um fim e que não está motivada quando não se sente impelida ou inspirada para a ação (RYAN \& DECI, 2000a). A motivação pode ser definida como um estado energético interno que dirige o comportamento ou a ação, e se relaciona com direção e persistência (RYAN \& DECI, 2000a), (RYAN \& DECI, 2007). Segundo Deci e Ryan (1985), a energia é, fundamentalmente, uma questão de necessidades: as necessidades inatas e as necessidades que se adquirem nas interações com o meio. A direção abrange os processos e as estruturas que dão significado aos estímulos internos e externos, direcionando a ação para a satisfação das necessidades. No estudo da motivação, a distinção mais básica e clássica ocorre entre a motivação intrínseca e a motivação extrínseca (DECI \& RYAN, 1985).

Na motivação intrínseca, a pessoa propõe-se a realizar algo ou envolve-se numa tarefa, porque esta é inerentemente agradável ou interessante, corresponde a um desejo genuíno, uma tendência inata do ser humano para explorar o mundo, a ação é vista como um fim em si mesma. Ao contrário, na motivação extrínseca, a pessoa realiza algo para alcançar determinado resultado, a ação vem responder a pressões externas, ou porque é útil para atingir determinado objetivo, independentemente da ação em si (MINER, 2015).

Nesta pesquisa foi trabalhada a motivação extrínseca de forma contínua e personalizada, e para atingir este objetivo foi delineado um sistema que veremos com mais detalhes na próxima seção.

\section{Metodologia}

Este trabalho teve cunho qualitativo, buscando um nível de realidade que dificilmente pode ser quantificado (FLICK, 2009). Esse tipo de estudo compreende o sujeito e o objeto de pesquisa de forma contextualizada e inter-relacionada, algo de difícil percepção em dados estatísticos e mensuráveis.

O sistema HIGIA, delineado para dar suporte às atividades de pesquisa envolve um ambiente de mundo virtual povoado por cenários especialmente delineados e por 
agentes pedagógicos que interagiram com o usuário apoiados por um serviço de chatterbot que age mutuamente em tempo real via smartphone, após receber e analisar os dados de um sensor de movimentação. O sistema foi estruturado conforme a Figura 1.

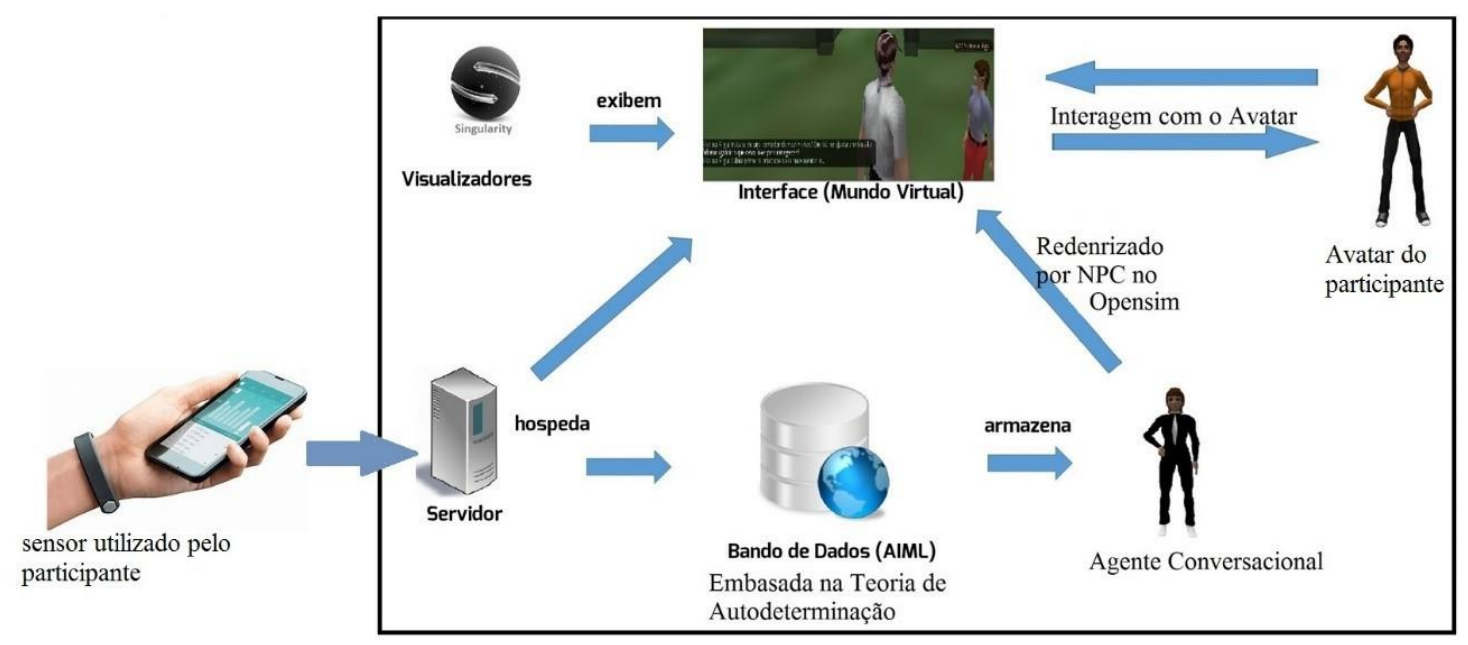

Figura1: Esquema do Sistema HIGIA

Como dito anteriormente, este artigo, irá se ater no referencial teórico e como este foi aplicado, a parte técnica e estrutural deste sistema não será visto. O sistema HIGIA foi construído sob uma arquitetura cíclica, que será detalhada nesta seção. De acordo com Nevado (2009), a arquitetura pedagógica (AP) pode ser definida como "suporte estruturante" para a aprendizagem. Segundo Sgobbi et al. (2014a) o caráter das arquiteturas pedagógicas é pensar a aprendizagem como uma construção a partir da vivência de experiências, de reflexões e metarreflexões do sujeito, em interação com o seu meio ambiente socioecológico. Nesse sentido, envolvem construção de estratégias pedagógicas embasada numa determinada teoria e seus pressupostos a fim de auxiliar na efetivação da aprendizagem com suporte de recursos tecnológicos.

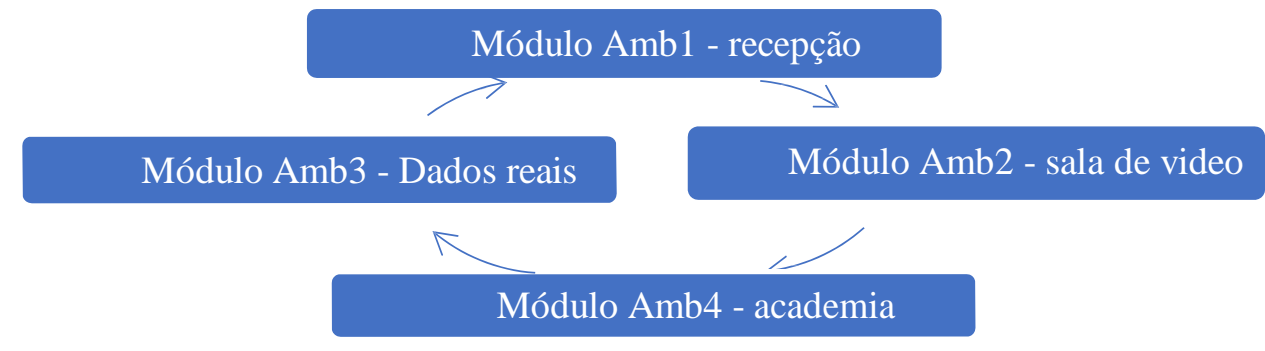

Figura 2 - Recursos tecnológicos inerentes à arquitetura pedagógica do HIGIA

A Figura 2 apresenta como está disposta à realimentação no sistema HIGIA, em função da pedagogia escolhida e de suas metas. Tais módulos se combinam dentro do mundo virtual.

Módulo do Ambiente 1 (Recepção) - Buscou-se por meio da configuração intencional do ambiente (motivação visual para as questões a serem trabalhadas) e interações com agente, que apresentou a função enviar questões instigadoras. Nesse ambiente, existe uma sala que oferece opções para a customização do avatar do participante. É importante ressaltar que a capacidade de personalizar seu avatar e usá -lo para interagir com outras pessoas e entidades, enseja uma nova forma de fazer valer a 
própria subjetividade corporificada. $\mathrm{O}$ efeito da experiência de alguém em um mundo virtual, é empoderador, pois este irá modificar sua aparência e passar a exibir características relacionadas a como gostaria de ser e/ou como se enxerga, chamado o efeito Protheus (YEE,2007). Esse efeito ocasiona, uma transferência de expectativas ou entendimentos de comportamento do seu avatar para o seu próprio comportamento no mundo real.

Módulo do Ambiente 2 (sala de vídeo) - Nesse ambiente são demonstrados exercícios e é feito todo o esforço para motivar o usuário a imitá-los, vários tipos de mídias (QRcode, vídeos, sons) são utilizadas para envolver o participante. Conforme Taube (2015) ressalta, existe uma relação de reforço entre observar uma ação e imitar essa ação. O agente conversacional, nesse ambiente, realiza demonstrações, comenta os benefícios dos exercícios e ressalta aspectos importantes do mesmo. Perguntas instigadoras de reflexão foram formuladas e são questionadas pelo agente em função do que está sendo apresentado. Cabe observar que durante as incursões do usuário no mundo virtual novos desafios foram constantemente apresentados conforme sugerido por Vrazel (2008).

Módulo do Ambiente 3 (dados reais) - o comportamento do agente conversacional deriva da análise dos dados externos (originários dos sensores reais utilizados pelos participantes da pesquisa) que busca criar motivação extrínseca, com vistas a incentivar pequenas metas atingíveis e/ou pequenos estímulos positivos. A Teoria da Autodeterminação permite pautar a compreensão dos componentes da motivação intrínseca e extrínseca e os fatores relacionados com a sua promoção, pautando a construção da estratégia de interação do agente com o participante nesse ambiente (Sgobbi et al., 2014b).

Módulo Ambiente 4 (academia de ginástica) - este local foi povoado por avatares com biótipos de aparências físicas variadas sem predominância de figuras excessivamente esbeltas, buscando controle de obesidade em comportamentos saudáveis (atividades físicas) que pareciam realizar com facilidade e satisfação. Foi disponibilizado ao participante a possibilidade de colocar seu próprio avatar em modo de execuç ão de exercícios, o que ofereceu maior sensação de identificação com a atividade e maior predisposição para sua repetição no mundo real e resultou em maior incentivo para o envolvimento com a atividade de exercício físico.

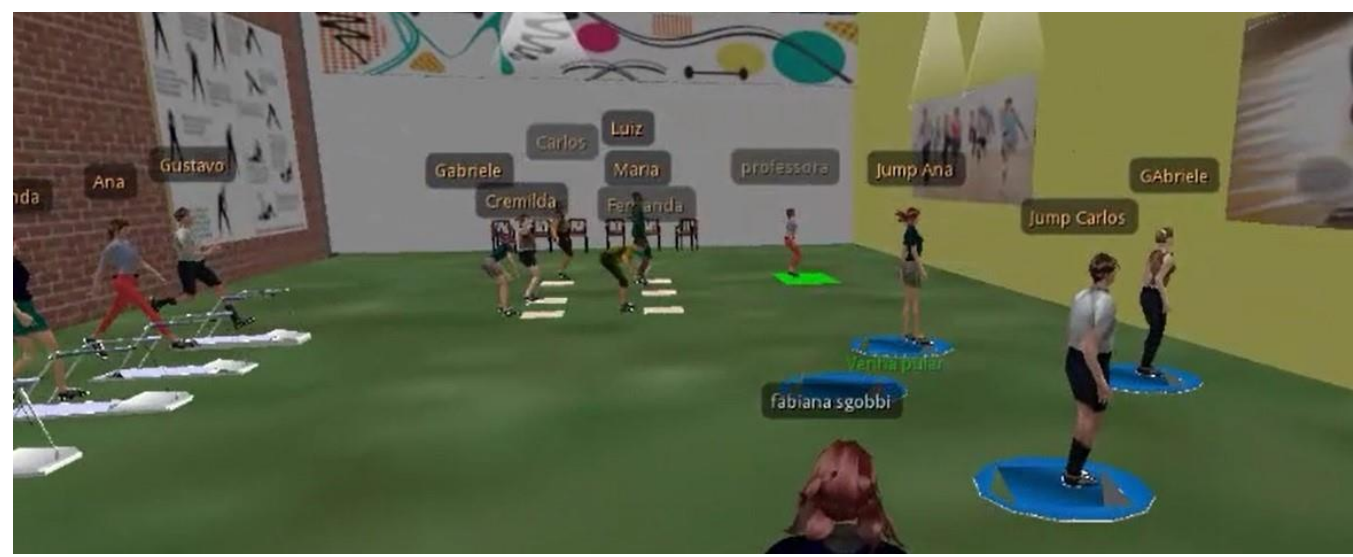

Figura 3 - Academia do Sistema HIGIA

Os princípios da Teoria da Autodeterminação apontam que as motivações dos indivíduos diferem, sendo determinadas e orientadas por contextos que dão subsídios a necessidades psicológicas com diferentes manifestações. Assim, tais peculiaridades 
precisam ser consideradas no processo de motivação dos obesos com vistas à aprendizagem (WATSON et al., 2017).

Afim de oferecer outras soluções o sistema apresentou algumas alternativas de exercícios ao ar livre, como pode ser visto na figura 4.

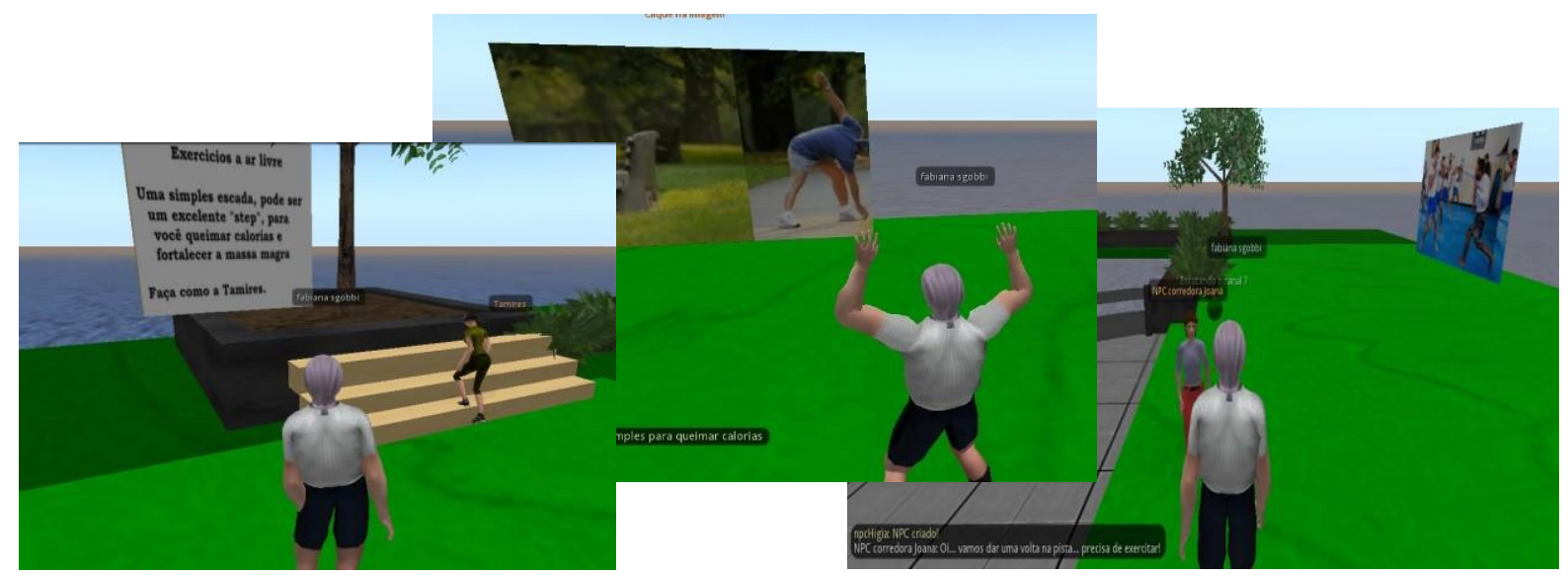

Figura 4: Propostas de diferentes exercícios em ambientes abertos

Além da academia (vista na figura 3) e as demais estações de intervenções (como sala de mídias) o Sistema HIGIA, também contou com intervenções, ao ar livre (apresentadas na figura 4). Aspinall et al. (2015) afirmam que exercícios ao ar livre promovem maior sensação de revitalização, aumento de energia e motivação, juntamente à diminuição da tensão, raiva, confusão mental e depressão.

Foram analisados todos os diálogos ocorridos (entre participantes e agentes conversacionais) durante os 3 meses de intervenção. É relevante ressaltar que a base de dados do agente conversacional também foi utilizada para enviar, via smartphone, mensagens motivadoras diariamente aos participantes.

\section{1 - Procedimento do experimento:}

O primeiro contato com o Sistema HIGIA foi realizado com orientação presencial a fim de facilitar a familiarização e navegação no mundo virtual. Antes de começarem a receber as intervenções os 3(três) participantes, responderam as três versões do questionário de autorregulação e na sequência foram medidos (circunferência abdominal) e pesados, tal procedimento se deu ao final de cada uma das 3 etapas, somando 4 questionários (com 3 versões cada um) e 4 medições.

$\mathrm{Na}$ primeira etapa, cada indivíduo ficou com o pedômetro (sensor de movimentação), durante 1 mês, eles foram orientados a visitar e interagir com HIGIA, ao menos 2 vezes por semana e realizar a lista de tarefa dentro do mundo virtual. Na segunda etapa da pesquisa, os participantes não tiveram acesso ao mundo virtual do Sistema HIGIA e continuaram utilizando o pedômetro e recebendo estímulos via smartphone. Essa etapa teve duração de 1 mês, eles continuaram recebendo mensagens do Sistema e recebendo os estímulos do pedômetro (o aparelho estipula uma meta, que quando o usuário atinge e emite um aviso sensorial). Na terceira etapa, os participantes não receberam estímulos motivacionais diretos. Consistiu em uma etapa para analisarmos se houve internalização da motivação.

\section{Análise de Dados}

A pesquisa contou com diversas ferramentas de análise de dados: análise gráfico dos dados do pedômetro, análise de relato e resumo das intervenções no Sistema HIGIA, 
análise dos dados corporais, análise dos diálogos com os agentes conversacionais e análise do questionário de autorregulação. Atendendo o foco deste artigo será apresentado apenas última análise citada, tendo em mente um recorte da utilização da teoria de autodeterminação.

Para realizar a análise é preciso relembrar os conceitos de autorregulação. A Teoria de Autodeterminação diferencia tipos de regulação comportamental em termos do grau em que eles representam um funcionamento autônomo ou autodeterminado (versus controlada). A motivação intrínseca é o principio no contínuo de autodeterminação da atividade autônoma; quando as pessoas estão, intrinsecamente, motivadas, elas estão por definição autodeterminadas. No entanto, o questionário de Autorregulação diferencia os tipos de motivação extrínseca em termos do grau em que ela foi internalizada, sugerindo que o mais completamente internalizado e integrado consigo mesmo, será a base para o comportamento autônomo (quanto mais internalizado o comportamento, mas autônomo ele será).

Existem quatro tipos diferentes de regulação comportamental, na Teoria de Autodeterminação. Eles definem em termos do grau em que a regulamentação de uma atividade extrinsecamente motivada tem sido internalizada e integrada. Eles são a regulação externa, regulação introjetada, regulação identificada e regulação integrada; em ordem do menos para o mais completamente internalizado. No quadro abaixo ilustra os níveis de motivação extrinseca.

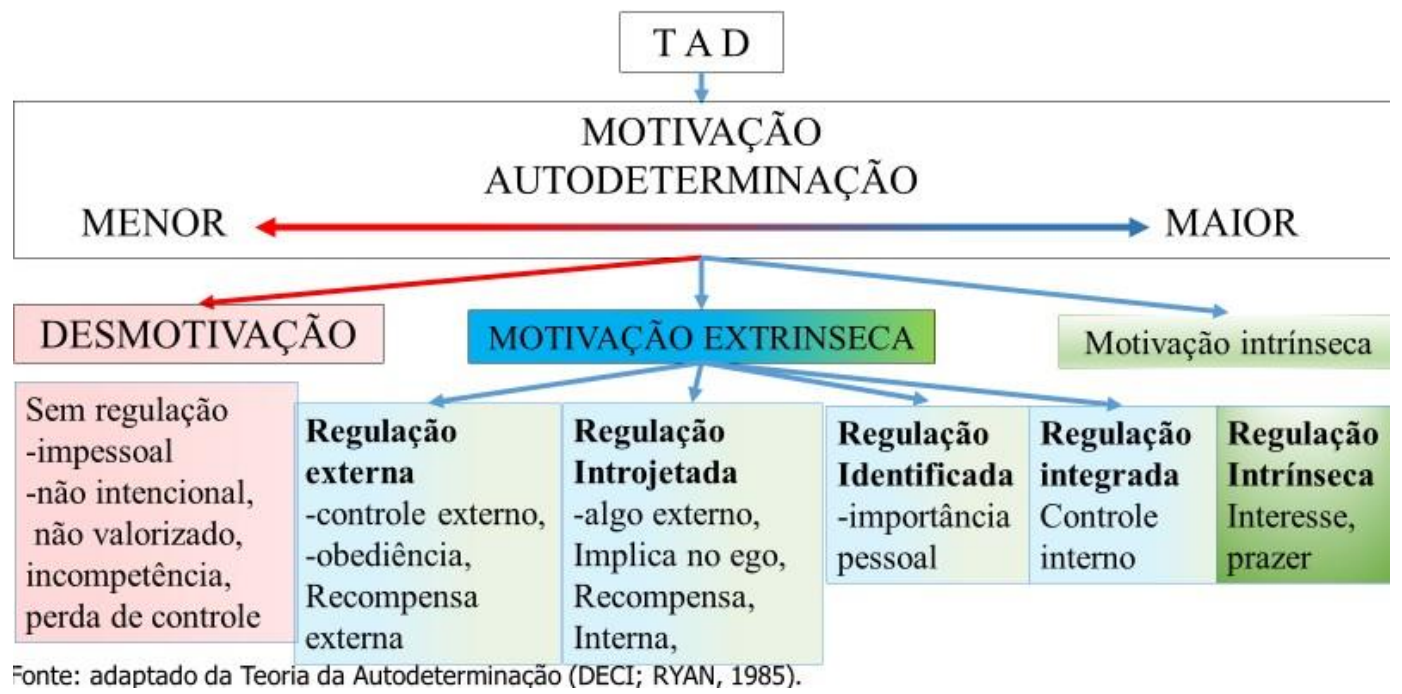

Figura 5: Quadro ilustrando os níveis de motivação da TAD

Foram aplicados os questionários de autorregulação por 4 vezes, nesta pesquisa, seguindo os preceitos de Ryan e Deci (2000), afim de identificar o nível de motivação em cada etapa da pesquisa. Foram utilizadas as três versões do questionário para atender a diversos tipos de modalidades de atividades físicas (um modelo direcionado a treino de musculação, o segundo direcionado para atividades aeróbicas em academias e o terceiro para atividades físicas livres).

Os questionários se subdividem em 3 grandes áreas de atividades físicas: motivação para treinar (musculação), motivação para fazer ginástica em academia e a motivação para se exercitar (livremente). Esses questionários dizem respeito às razões pelas quais uma pessoa se exercita regularmente. É estruturado de forma que as perguntas e respostas que representam regulação externa, regulação introjetada, regulação identificada e motivação intrínseca. A questão básica refere-se ao grau em que a pessoa 
se sente autônoma em relação ao exercício ou a prática de atividade física. Os questionários são muito semelhantes - isto é, os itens introjetados sobre uma escala são semelhantes aos itens introjetados nas outras escalas. No entanto, as três versões diferentes foram desenvolvidos por investigadores do grupo de pesquisa de Ryan e $\operatorname{Deci}(2000)$.

Será apresentada as instruções para utilização e cálculo dos níveis de autorregulação para munir o leitor de dados sobre a técnica e aplicação do questionário de autorregulação. Existem vários motivos pelos quais as pessoas se exercitam. Esses questionários, buscam identificar o nível de regulação da motivação. Os três tipos de questionários têm a mesma forma de pontuar, porém, com escalas distintas.

Para melhor ilustrar, temos um exemplo de parte do questionário de autorregulação para musculação.

Exemplo:

Indique como verdadeira cada um destes razão é por que você trabalha para fora.

A escala é:

\begin{tabular}{|c|r|r|r|r|r|r|}
\hline 1 & 2 & 3 & 4 & 5 & 6 & 7 \\
\hline $\begin{array}{c}\text { Não é tudo } \\
\text { verdade }\end{array}$ & & & $\begin{array}{c}\text { Alguma coisa é } \\
\text { verdade }\end{array}$ & & & $\begin{array}{c}\text { Tudo é } \\
\text { verdade }\end{array}$ \\
\hline
\end{tabular}

Por que você treina?

1.Porque eu simplesmente gosto de treinar.

2.Porque treinar é importante e tras benéfico para a minha saúde e estilo de vida.

3.Porque eu me sinto mal sobre mim mesmo se eu não fazê-lo.

Nota-se que quanto menor o número, menor o nível de concordância com a resposta. Para analisar o resultado do questionário, primeiramente, deve-se classificar cada questão em sua subescalas: Regulação Externa, Regulação Introjetada, Regulação identificado e Motivação Intrínseca. Para fazer esta classificação é preciso seguir as tabelas de Níveis de Regulação. Cada versão possue sua tabela especifica.

A Primeira versão do questionário de autorregulação, buscou questionar motivação para fazer exercícios de força, treinar a musculação. O questionário de treino muscular consiste em 12 questões que possuem uma escala de 1 a 7 (onde 1 corresponde a total concordância com a questão, e 7 a total discordância), cada questão faz parte de um grupo de regulação no contínuo da autodeterminação, por exemplo a questão número 1 diz respeito a quanto de motivação intrínseca (de 0 a 7). A Tabela 01 apresenta o nível de regulação de cada questão.

Tabela 01: Níveis de regulação para $1^{\mathrm{a}}$ versão do SQRE

\begin{tabular}{|c|c|}
\hline Nível de regulação & Número da questão \\
\hline Regulação externo(externas): & $5,7,12$ \\
\hline Regulação introjetada(introjetada): & $3,6,9$ \\
\hline Regulação Identificada (identificada): & $2,8,10$ \\
\hline Motivação intrínseca(intrínseca): & $1,4,11$ \\
\hline
\end{tabular}

Fonte: Adaptada de Zeldman, Ryan e Fiscella (1999).

Para analisar é necessário calcular os níveis com seus respectivos valores. 
Tabela 02: Exemplo do cálculo de autorregulação

\begin{tabular}{|l|c|}
\hline \multicolumn{1}{|c|}{ Nível de regulação } & Respostas do participante LS \\
\hline Regulação externo(externas): & $\mathbf{7 + 6 + 7}$ \\
\hline Regulação introjetada(introjetado): & $4+7+1$ \\
\hline Regulação Identificada (identificados): & $2+4+4$ \\
\hline Motivação intrínseca(intrínseca): & $1+4+4$ \\
\hline
\end{tabular}

Fonte:adaptada de Zeldman, Ryan e Fiscella (1999)

$\mathrm{Na}$ tabela 02 é possivel visualizar um exemplo de calculo realizado. Devem-se somar os valores correspondentes, maior somatoria indica o nível de regulação. Nesse caso tem-se a regulação externa.

Pode-se usar o resultado das subescalas individuais em suas análises e, também, usar o Índice de Autonomia Relativa (RAI) . Para calcular o RAI, primeiro usa-se a tabela de Níveis de Regulação correspondente de cada versão, depois aplica-se a fórmula.

\section{X Intrínseca + identificados - introjetado - 2 X externas}

Finalmente, vale a pena notar que as subescalas do questionário de autorregulação, independentemente do número de subescalas de cada versão do questionário, podem ser combinadas para formar um Índice de Autonomia Relativa (RAI). Para formá-lo, a subescala externa é ponderada - 2 , a subescala introjetado é ponderada -1, a subescala identificado é ponderada +1 , e a subescala intrínseca é ponderada +2 . Em outras palavras, as subescalas controladas são ponderadas de maneira negativa e as subescalas autônomas são ponderadas de forma positiva. $\mathrm{O}$ mais controlado o estilo regulamentar representado por uma subescala, quanto maior o seu peso negativo; e o mais autônomo o estilo regulamentar representado por uma subescala, quanto maior o seu peso positivo.

Resumo dos Procedimentos de pontuação. Pode-se calcular os valores de estilo de autorregulação de duas maneiras em diferentes análises. Primeiramente, usamos cada pontuação subescala, separadamente, nas análises de modo que os participantes têm uma pontuação para cada estilo, como visto na tabelas de Níveis de Regulação. A segunda forma implica em calcularmos o Índice de Autonomia Relativa pela ponderação das subescala e combiná-los, utilizando a fórmula (GROLNICK \& RYAN , 1989).

Foram utilizadas três versões de questionários de autorregulação, onde todos têm a mesma forma de cálculo, porém cada qual possui um número variado de questões e sua respectiva tabela de níveis de regulação, a qual foi extraída dos estudos de Ryan e $\operatorname{Deci}(2000)$.

Após a aplicação de análise dos questionários de autorregulação, foi possível verificar que houve um aumento no nível de motivação nos participantes.

\section{Conclusões}

Os estudos desta pesquisa possibilitaram ensejar a motivação com validação do Sistema HIGIA, que disponibilizou o uso da triangulação entre aprendizagem em mundo virtual, o uso da Teoria de Autodeterminação e o feedback (de dado/tempo real) no mundo virtual e via SMS em seu smartphone.

Os feedbacks em relação ao mundo virtual foram realizados por meio da utilização da linguagem textual, oral, gestual e gráfica, potencializando, dessa forma, as representações das percepções e o sentimento de imersão. Esse tipo de retorno faz com o participante se sinta parte atuante de seu processo. Segundo Liz et al. (2013), o feedback é o motor da motivação e pode ser classificado como intrínseco (inerente) ou extrínseco (aumentado). O feedback intrínseco é a informação obtida pelos órgãos sensoriais, sem depender de uma fonte externa, enquanto o feedback extrínseco é a informação obtida por 
meio de um outro indivíduo ou algum meio artificial (o participante recebia mensagens via SMS de seu smartphone e seu sensor emitia avisos sensoriais).

Após analise os questionários de autorregularão, utilizando as regras e protocolos da teoria de autodeterminação, foi possível constatar que os participantes evoluíram de um estado não motivado à realização de atividade física, para um estado de comprometimento pessoal, embora, ainda, não caracterizado como motivação intrínseca, pois, quando cessaram os estímulos, houve queda no comprometimento com a manutenção do esforço de realização de atividade física. Segundo a Teoria de Autodeterminação, eles teriam alcançado um estágio de motivação controlada para a motivação com regulação introjetada. Este conceito constata, que os indivíduos tiveram uma grande evolução no nível de motivação.

Durante o tempo de intervenção com o "sistema HIGIA", houve um grande envolvimento, que resultou com importantes perdas de peso (média de $6 \mathrm{Kg}$ na primeira etapa e $3,5 \mathrm{Kg}$ na segunda etapa) e um aumento de $70 \%$ de movimentação em relação à quantidade usual de movimentação informada pelos participantes na entrevista inicial. Dessa forma a pesquisa pode comprovar que, dado o estímulo virtual, com o acompanhamento não intrusivo de um sensor e a apresentação constante e diversificada de motivação, puderam promover uma modificação na busca de qualidade de vida.

Na terceira etapa, quando todos os estímulos cessaram, a motivação, que ainda não estava internalizada (DECI \& RYAN, 1985), começou a esmaecer diminuindo a intensidade de movimentação. Isto permite pressupor que, se houvesse uma academia virtual para indivíduos almejando mudar sua qualidade de vida, poderiam obter vantagens e apoio significativo se pudessem usar um mundo virtual com condições estimuladoras do novo comportamento e sensores associados para aferir de forma continuada dados relacionados com o novo comportamento desejado.

Em estudos futuros, cada indivíduo poderia, além de adquirir seu próprio sensor, o que já constitui uma tendência de mercado atual, obter o apoio motivacional do mundo virtual HIGIA, recebendo todas as intervenções do Sistema (participar da academia virtual regularmente, receber dicas via smartphone, assistir vídeos etc.) informando seu peso mensalmente e sincronizando o seu sensor e, assim, continuar a vivenciar um contexto positivo de motivação para melhoria de qualidade de vida.

\section{Referencial Bibliografico}

ASPINALL, P.; MAVROS, P.; COYNE, R.; ROE, J. (2015). The urban brain: analysing outdoor physical activity with mobile EEG. Br J Sports Med, 49(4), 272276.

DECI, E. L.; RYAN, R. M. Intrinsic motivation and self-determination in human behavior. New York: Plenum, 1985.

DECI, E.L.; RYAN, R.M. Facilitating optimal motivation and psychological wellbeing across life's domains. Canadian Psychology, 49 (1), 14-23, 2008.

FLICK, UWE. Desenho da pesquisa qualitativa. In: Pesquisa qualitativa. Artmed, 2009.

GROLNICK, WENDY S.; RYAN, RICHARD M. Parent styles associated with children's self-regulation and competence in school. Journal of educational psychology, v. 81, n. 2, p. 143, 1989.

MINER, J. B. Organizational behavior 1: Essential theories of motivation and leadership. $\quad$ Routledge, $2015 . \quad$ Disponível em https://books.google.com.br/books?hl=en\&lr=\&id=YXOsBwAAQBAJ\&oi=fnd\&pg=P 
P1\&dq=motivation\&ots=3A6Sdy2aeh\&sig=fQP8sorgixgNjNhl5tZ5xTThnP4\&redir_es $\mathrm{c}=\mathrm{y} \# \mathrm{v}=$ onepage $\& \mathrm{q}=$ motivation $\& \mathrm{f}=$ false. Acessado em 2/01/2016.

NEVADO, ROSANE ARAGÓN DE; DALPIAZ, MARIA MARTHA; DE MENEZES, CREDINÉ SILVA. Arquitetura pedagógica para construção colaborativa de conceituações. In: Anais do Workshop de Informática na Escola. 2009. p. 1653-1662.

RYAN, RICHARD M.; DECI, EDWARD L. (2000a) Intrinsic and extrinsic motivations: Classic definitions and new directions. Contemporary educational psychology, v. 25, n. 1, p. 54-67, 2000a. Disponível em http://www.sciencedirect.com/science/article/pii/S0361476X99910202 Acessado em 06/10/2015.

RYAN, RICHARD M.; DECI, EDWARD L. Self-determination theory and the facilitation of intrinsic motivation, social development, and well-being. American psychologist, v. 55, n. 1, p. 68, 2000b.

RYAN, R. M., CONNELL, J. P. Perceived locus of causality and internalization: Examining reasons for acting in two domains. Journal of Personality and Social Psychology, 57, 749-761. doi:10.1037/0022-3514.57.5.749, 1989.

SGOBBI, F. S.; NUNES, F. B.; TAROUCO, L. A utilização de agentes inteligentes no apoio ao autocuidado de idosos. RENOTE. Revista Novas Tecnologias na Educação, v. 12, p. 1-10, 2014.Disponível em http://seer.ufrgs.br/index.php/renote/article/view/53520.

SGOBBI, F. S., NUNES, F. B., BOS, A. S., BERNARDI, G., TAROUCO, L. M. R. Interação com artefatos e personagens artificiais em mundos virtuais. In Brazilian Symposium on Computers in Education (Simpósio Brasileiro de Informática na Educação-SBIE) (Vol. 25, No. 1, p. 642), (2014b).

TAUBE, WOLFGANG; MOUTHON M; LEUKEL C; HOOGEWOUD H; ANNONI J, KELLER M. Brain activity during observation and motor imagery of different balance tasks: An fMRI study. Córtex Volume 64, March. 2015, Pag. 102-114 Disponível em http://www.sciencedirect.com/science/article/pii/S0010945214003153.

VRAZEL, JOELLEN; SAUNDERS, RUTH P.; WILCOX, SARA. An overview and proposed framework of social-environmental influences on the physical-activity behavior of women. American journal of health promotion, v. 23, n. 1, p. 2-12, 2008.

WATSON, POPPY; WATSON, P., WIERS, R. W., HOMMEL, B., GERDES, V. E.. Stimulus Control over Action for Food in Obese versus Healthy-weight Individuals. Frontiers in Psychology, v. 8, 2017.

YEE N, BAILENSON J. The Proteus effect: the effect of transformed selfrepresentation on behavior. Hum Commun Research, v 33, n. 3, p:271-90; 2007.

ZELDMAN, A.; RYAN, R. M.; FISCELLA, K. Attitudes, beliefs and motives in addiction recovery. Unpublished manuscript, University of Rochester, Rochester, NY, 1999. 